\title{
The re-emergency and persistence of vaccine preventable diseases
}

\author{
RODRIGO C.N. BORBA, VINÍCIUS M. VIDAL and LILIAN O. MOREIRA \\ Universidade Federal do Rio de Janeiro, Faculdade de Farmácia, Departamento de Análises Clínicas \\ e Toxicológicas, Laboratório de Bacteriologia e Imunologia Clínica, Centro de Ciências da Saúde, \\ Bloco A, $2^{\circ}$ andar, Sala 7, Ilha do Fundão, 21941-617 Rio de Janeiro, RJ, Brasil \\ Manuscript received on December 15, 2014; accepted for publication on February 26, 2015

\begin{abstract}
The introduction of vaccination worldwide dramatically reduced the incidence of pathogenic bacterial and viral diseases. Despite the highly successful vaccination strategies, the number of cases among vaccine preventable diseases has increased in the last decade and several of those diseases are still endemic in different countries. Here we discuss some epidemiological aspects and possible arguments that may explain why ancient diseases such as, measles, polio, pertussis, diphtheria and tuberculosis are still with us.
\end{abstract}

Key words: diphtheria, measles, pertussis, polio, tuberculosis, vaccine.

\section{INTRODUCTION}

Vaccination is still the most successful method to prevent infectious diseases. Since the introduction of public immunization against smallpox by Jenner in the $18^{\text {th }}$ century, vaccines have drastically reduced the number of deaths caused by infectious diseases. The best achievement of immunization programs are the induction of long-term protection against life-threatening consequences of infectious disease. This is obtained by the generation of protective immunity elected by antibodies and antigen specific $\mathrm{B}$ and $\mathrm{T}$ cells, which lead to protection. Despite global public health successes of vaccines, to date, the only eradicated disease is smallpox. Nevertheless, several other diseases were eliminated, meaning it stopped circulating in certain region of the globe, for example polio in the

Correspondence to: Lilian de Oliveira Moreira

E-mail: lilian@pharma.ufrj.br
United States by the end of 70s and in Brazil by the end of the 80's (Albert et al. 2001, WHO 2014a).

There are several reasons that may explain the permanence of certain diseases, preventing its eradication. These reasons range from the rise of more virulent clones that are resistant to vaccineinduced immunization (Zakikhany and Efstratiou 2012, Mills et al. 2014), to more recent observations in which parents choosenot to vaccinate their children, due to concerns about vaccine safety. All this contributed to the resurgence of certain vaccine preventable diseases (Wolfe and Sharpe 2002, Godlee et al. 2011, History of vaccines 2014). In fact, anti-vaccination movements exist since the first immunization campaigns. Futhermore, public opinion may vary for several reasons depending of cultural or religious points of view. Controversies over the efficacy, safety, and morality of compulsory immunization stem from the longstanding tension between two, sometimes 
divergent, goals: to protect individual liberties and safeguard the public's health (Rodgers et al. 1993, Parmet et al. 2005, Salmon and Omer 2006). In addition, compromised vaccination in several war areas, such as Syria (Aylward and Alwan 2014) and Afghanistan (Rutter and Donaldson 2014) exposed these populations to different disease burdens. Furthermore, international travelling strongly contributes to disease spreading worldwide: in this scenario unvaccinated and immunocompromised groups are at the highest risk, and also may work as carries. For this reason, immunocompromised people - HIV, elderly, transplanted and cancer patients - should avoid travelling to endemic area, such as western Africa or south Asia (India, Pakistan and Afghanistan) where polio transmission still occurs. As a rule, live vaccines should be avoided in severely immunocompromised travelers due to risk of dissemination. However, in special circumstances, the use of inactivated vaccines could be an alternative.

Elderly people are also particularly susceptible to infections and therefore preventive vaccination is crucial. However, this population presents a lower ability to mount an effective immune response to vaccination since both innate and adaptive immune system functions are affected by aging. Due to the increase of incidence of pertussis in adults, vaccination against the disease is strongly recommended in US for example. Vaccination of the elderly remains the best strategy to prevent infection, but is suboptimal because of immunosenescence. Thus, lifelong vaccination programs should be promoted in order to achieve the herd immunity threshold, moving from the current concept of childhood-based vaccination to a more balanced lifelong vaccination schedules (Lang and Aspinall 2012).

Polio, measles and pertussis (whooping cough) are diseases related with recent outbreaks. Moreover, tuberculosis and diphtheria remain observed and are endemic in several areas of the globe. Endemic diseases and outbreaks are particularly threatening since the microbe can easily be spread by traveling residents and visitors. Furthermore, unvaccinated people are vulnerable and may serve as reservoirs, increasing the problem. Here, we will focus on bacterial and viral diseases that, despite high vaccination rates, are still endemic or have reemerged in the past decade.

MEASLES

Measles is a viral disease caused by members of the genus Morbillivirus. The disease is preventable by immunization with the measles, mumps and rubella (MMR) vaccine.

Measles is a potentially deadly viral disease, especially for unvaccinated children. It spreads easily from person to person via droplets from the nose, mouth or throat of infected people. Symptoms include high fever, running nose, bloodshot eyes and tiny white spots on the inside of the mouth followed by a rash on the face and upper neck and gradually spreading downwards. Most people recover within 2-3 weeks, however measles can cause serious complications, including blindness, encephalitis, severe diarrhea, ear infection and pneumonia, particularly in malnourished children and people with reduced immunity (WHO 2014b). Nowadays, because the disease has been absent in several countries, the symptoms of measles are not always easily identified by doctors and parents leading to misidentification of cases.

Measles is endemic in several areas of the globe (Fig. 1). In 2013, 194.139 cases of measles were reported and 145.700 deaths documented worldwide (WHO 2014c). The disease returned in countries where it was considered eliminated. In the US for example, 644 cases of measles were reported in 2014, three times more than what was observed in 2013. The majority of people who got measles had not been vaccinated (CDC 2014a). This is particularly frightening, because the disease was considered eliminated since 2000. In Brazil, cases of measles also increased reaching more than 200 cases in 2013 (Fig. 2A) (WHO 2014g). 


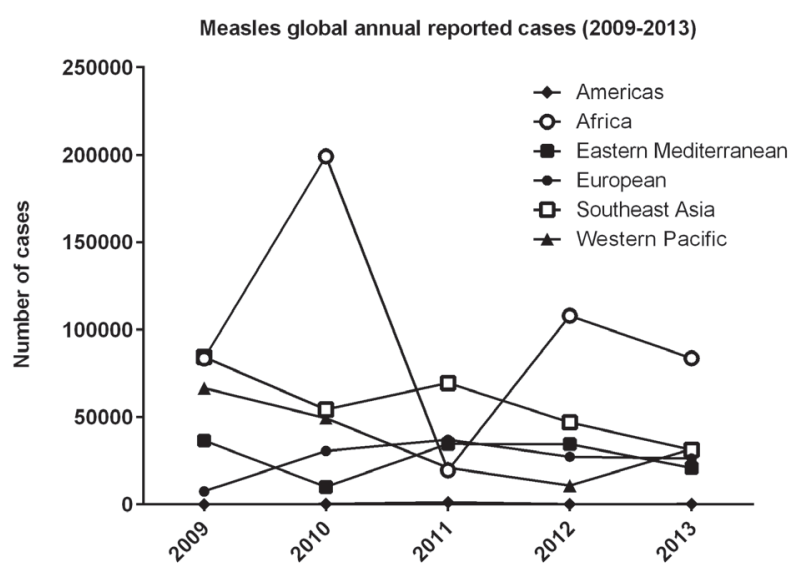

Figure 1 - Measles global annual reported cases (2009-2013). Countries are distributed by regions; data summarized from WHO (2014) http://apps.who.int/immunization_monitoring/ globalsummary/timeseries/tsincidencemeasles.html

Several studies have reported associations between measles antibody concentration and HIV infection and exposure; for example, infants born to HIV-infected women have lower levels of measles-specific transplacental antibodies, potentially leaving these infants at greater risk of infection before they receive the scheduled measles vaccination. Other reports have shown that HIV infection is associated with greater severity of measles disease, higher mortality and prolonged measles virus shedding (Polonsky et al. 2015).

Most importantly, the increase of measles in the US and other industrialized countries resulted from anti-vaccination movements which started 16 years ago following the statements made by a British doctor named Andrew Wakefield. Wakefield associated the MMR vaccine with diseases such as bowel disease and autism, arguing that the vaccine had not been properly tested prior to being used. Another argument of the anti-vaccination groups was that thimerosal, a mercury-containing compound used as a preservative in many vaccines, was associated with autism, however these claims were never proved (CDC 2014b, Williamson 1984, Wakefield et al. 1998, Wakefield and Montgomery 2001, Hackett 2008, Betáková et al. 2013).
A

Measles annual reported cases in Brazil (2003-2013)
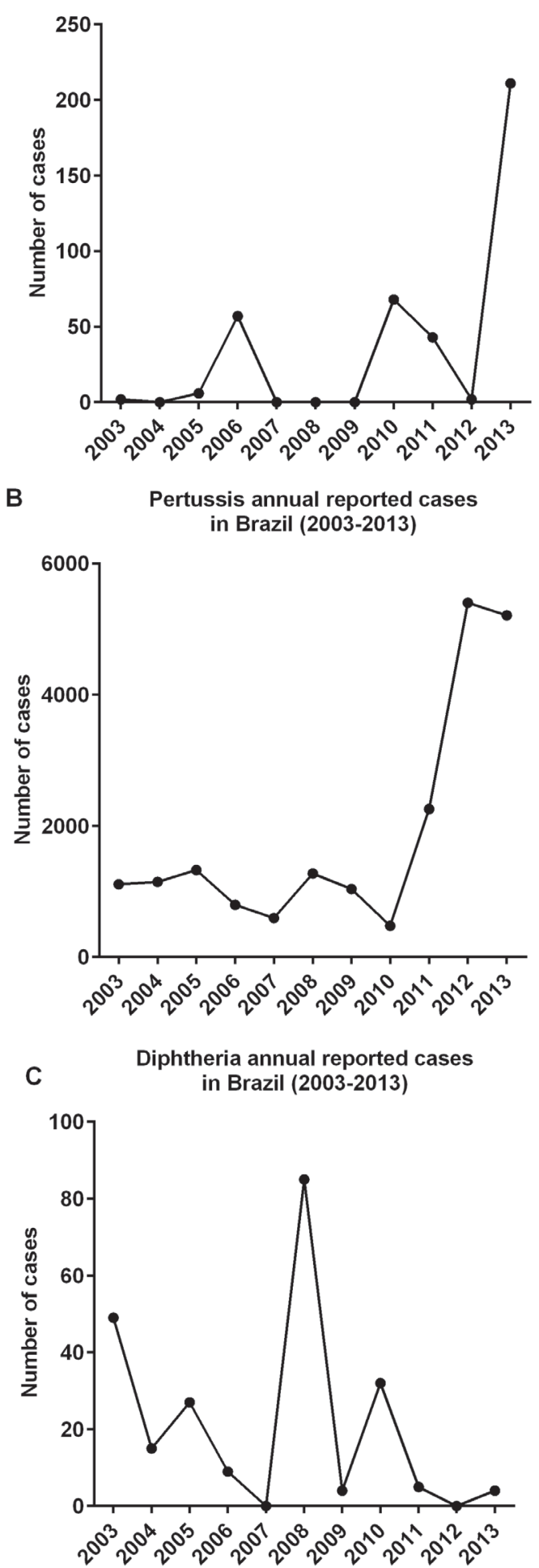

Figure 2 - Measles, pertussis and diphtheria annual reported cases in Brazil (2003-2013). A, measles; B, pertussis; C, diphtheria; data summarized from WHO (2014); http://apps. who.int/immunization_monitoring/globalsummary 
Following the claims made by these doctors, several groups of parents started a movement to reduce vaccination, generating public confusion and fear about vaccine safety. Additionally, some religious groups refuse vaccination, increasing their vulnerability to infectious that can spread quickly (Salmon and Siegel 2001, Salmon and Omer 2006). Even though, Wakefield's publication was retracted and evidences showed that he committed scientific fraud and gained financial profit by falsifying data (Godlee et al. 2011), the damage had already been done.

Recently, a systematic investigation reviewed more than 20.000 studies on adverse events of vaccines used for routine immunization of children from US (Maglione et al. 2014). The authors concluded that some vaccines are associated with adverse events; however these events are extremely rare and must be weighed against the protective benefits that vaccines provide. Adverse events, such as, sore arm or allergic reactions are tracked. Importantly, while all vaccines carry some small level of risk, the dangers of the illness exceed by far the dangers of the immunization (CDC 2014c, Maglione et al. 2014).

Although a large number of studies have demonstrated that there is no correlation between MMR vaccine and autism, anti-vaccine movements are still active and some parents are refusing to vaccinate their children (Stratton et al. 2001, Maltezou and Wicker 2013).

POLIO

Poliomyelitis, infantile paralysis or simply polio is a viral disease caused by a poliovirus. In most $(90$ to $95 \%$ ) people, the infection causes no symptoms, the remaining 5 to $10 \%$ present fever, diarrhea, headache, vomiting, neck rigorousness and pains in the arms and legs. The most severe cases of polio lead to paralysis and death (WHO 2014d). In the 80 's polio affected around 350.000 people in 125 countries. At that time, the World Health Assembly decided to launch the Global Polio Eradication

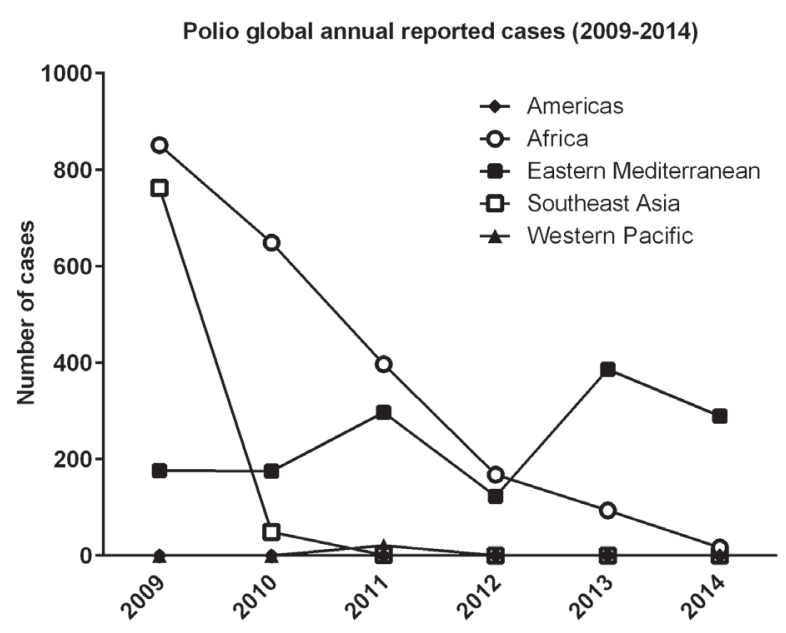

Figure 3 - Polio global annual reported cases (2009-2014). Countries are distributed by regions; data summarized from WHO (2014); http://apps.who.int/immunization monitoring/globalsummary; http:/www.polioeradication.org/ dataandmonitoring/poliothisweek.aspx

Initiative. In 2000, there was a reduction of $99 \%$ in the number of cases and in 2002 polio was eliminated in 118 countries (WHO 2014a).

Despite the excellent progress to control the disease spread, polio is still endemic in Afghanistan, Nigeria and Pakistan (Fig. 3) (Owais et al. 2013, WHO 2014d) alerting to the fact that the maintenance of the circulating virus is a constant threat to countries were polio was eliminated. In these countries, since 2011, 770 individuals, mainly young children, were paralyzed by polio (WHO 2014e). Nigeria and Pakistan have also exported wild poliovirus to no fewer than 20 other countries, affecting an additional 470 people (Rutter and Donaldson 2014).

Religious objections may contribute to endemic scenario in these countries. For example, in Southern Afghanistan the local Taliban called polio vaccination an American strategy to sterilize Muslim populations. Resistance to vaccination has even resulted in violent beatings and kidnappings (Warraich 2009). Similar objections halted polio vaccination campaigns in Nigeria years ago. In 2003, religious leaders in three different Nigerian 
states claimed that the vaccines were contaminated with HIV, sterilization and cancer-causing agents, despite tests confirming the vaccine's safety (Clements et al. 2006, Jegede 2007).

In 2013, a wild poliovirus spread from Pakistan to Syria, where it caused a substantial outbreak in the midst of civil war (Aylward and Alwan 2014).

Polio was considered eliminated in Syria 15 years ago, but now, because of defective child immunization caused by the civil war, there is a high risk that the disease could become endemic. Civil war also makes the surveillance difficult, therefore, several cases may be unaccounted for (Butler 2013; Roberts 2014). Healthy authorities alert that this is an emergency not just for Syria, where millions of kids are at risk, but also for surrounding countries, including Jordan, Lebanon, and Iraq, as refugees pour across the borders (Rutter and Donaldson 2014, Roberts 2014). Inadequate surveillance and suboptimal vaccination rates bring a real risk outbreak. In addition, many cases of polio do not present easily recognizable symptoms and, as a result, an infected person can remain unnoticed and spread the virus (Butler 2013).

Recent international spread of wild poliovirus has created a particularly complex outbreak of polio. Even though Europe is considered free of polio since 2002, surprisingly it is now vulnerable since poliovirus has re-emerged in Israel and Syria. Most countries in Europe use inactivated poliovirus vaccine (IPV) for immunization. IPV protects against all polio strains and induces a high level of individual protection, but it provides poor gut immunity. An alternative to IPV is the oral poliovirus vaccine (OPV), a weakened form of the live virus that provides strong gut immunity. It has been used for mass vaccinations and outbreak control because it is effective, cheap and easy to administer. However, in rare cases it can cause polio, so polio-free countries prefer to use IPV, which carries no such risk (Butler 2013). For that reason, the US for example, uses IPV, while in Brazil both vaccines are used for children vaccination (SBIM 2014).
Given the weaknesses in European polio defenses, the extensive levels of travel between Europe and Israel (42 infected people with no symptoms) and the millions of refugees fleeing Syria, there is a real risk of outbreaks in the European Union (EU) (Butler 2013). To prevent disease spreading, the new recommendations from WHO recommends residents and long term visitors to receive one dose of the vaccine (IPV or OPV) between 4 weeks and 12 months before international travel, and that those who are undertaking urgent travel have one dose of polio vaccine at least by the time of departure (Rutter and Donaldson 2014).

The international spread of wild poliovirus in 2014 is a public health emergency of international concern that shows how the world is vulnerable.

PERTUSSIS

Pertussis is an acute respiratory tract infection caused by Bordetella pertussis. Clinical manifestations include fever and a cough illness lasting at least 2 weeks with one of the following: paroxysms of coughing, inspiratory "whoop," or posttussive vomiting, without other apparent cause (WHO 2014f). The disease remains endemic (Fig 4A) and life-threatening, especially for the very young, mainly in unimmunized children in developing countries, with significant morbidity and mortality. In 2013, 136.036 cases and 89.000 deaths were reported. (WHO 2014f).

There are 2 types of vaccines against pertussis, a whole cell $(\mathrm{Pw})$ preparation which is composed of inactivated bacterial whole-cell, and a subunit vaccine also known as pertussis acellular $(\mathrm{Pa})$, that contains purified pertussis antigens such as pertussis toxin and filamentous haemagglutinin (FHA) (Witt et al. 2013; WHO 2014h). Both Pw and $\mathrm{Pa}$ vaccines are mixed with diphtheria and tetanus toxoids and absorbed in aluminum adjuvant (DTP vaccine). Because of its toxicity, the Pw preparation was discontinued in several countries such as the UK and US, however in Brazil both Pw and $\mathrm{Pa}$ remain on vaccine schedule (SBIM 2014). 
Although, considered safer, the Pa vaccine does not induce a robust immune response as compared to the $\mathrm{Pw}$ vaccine, since the effectiveness of acellular vaccines in preventing typical whooping cough ranges from $59 \%$ to $85 \%$. It was demonstrated that having a whole-cell vaccine as any part of the vaccination series improved immunity (Sheridan et al. 2012, Witt et al. 2013). In addition it was shown that $\mathrm{Pa}$ may protect against the disease, but does not prevent bacterial infection and transmission (Warfel et al. 2013).

Pertussis incidence increased dramatically in US, Australia and UK (Fig. 4B) (CDC 2014e, WHO 2014g).This re-emergence was also observed in Brazil where more than 5000 cases were reported in 2013 (Fig. 2B). It remains unclear why is pertussis incidence rising in different countries worldwide. Several considerations could explain the reason for this phenomenon. One strong argument is that the switch from $\mathrm{Pw}$ to $\mathrm{Pa}$ in the mid-1990s reduced the vaccine efficacy. Another possibility is that antigenic variation of circulating $B$. pertussis strains decrease protection against antigens used in the $\mathrm{Pa}$ vaccine. Alternatively, it is possible that $\mathrm{Pa}$ does not include the combination of $B$. pertussis components required to induce the appropriate antigen-specific immune responses that mediate protection (Mills et al 2014). In addition, the immunity generated by pertussis natural infection or by the vaccine is not long-term (Guiso 2014). Furthermore, reduction in vaccination rates against pertussis may also contribute to disease burden (Gangarosa et al. 1998, Baker 2003).

It is important to point out that the diagnosis of $B$. pertussis is particularly difficult. The bacteria can be isolated in a small period of time (catahral stage) during the course of the disease, plus the microbe is only found in the nasopharynges making the clinical specimen recovery challenging for unprepared staff. Besides that, the disease incidence is increasing not only in children, but also in adults and adolescents that sometimes do not present the classical disease symptoms (Clark 2014, Hartzell and Blaylock 2014). Altogether,
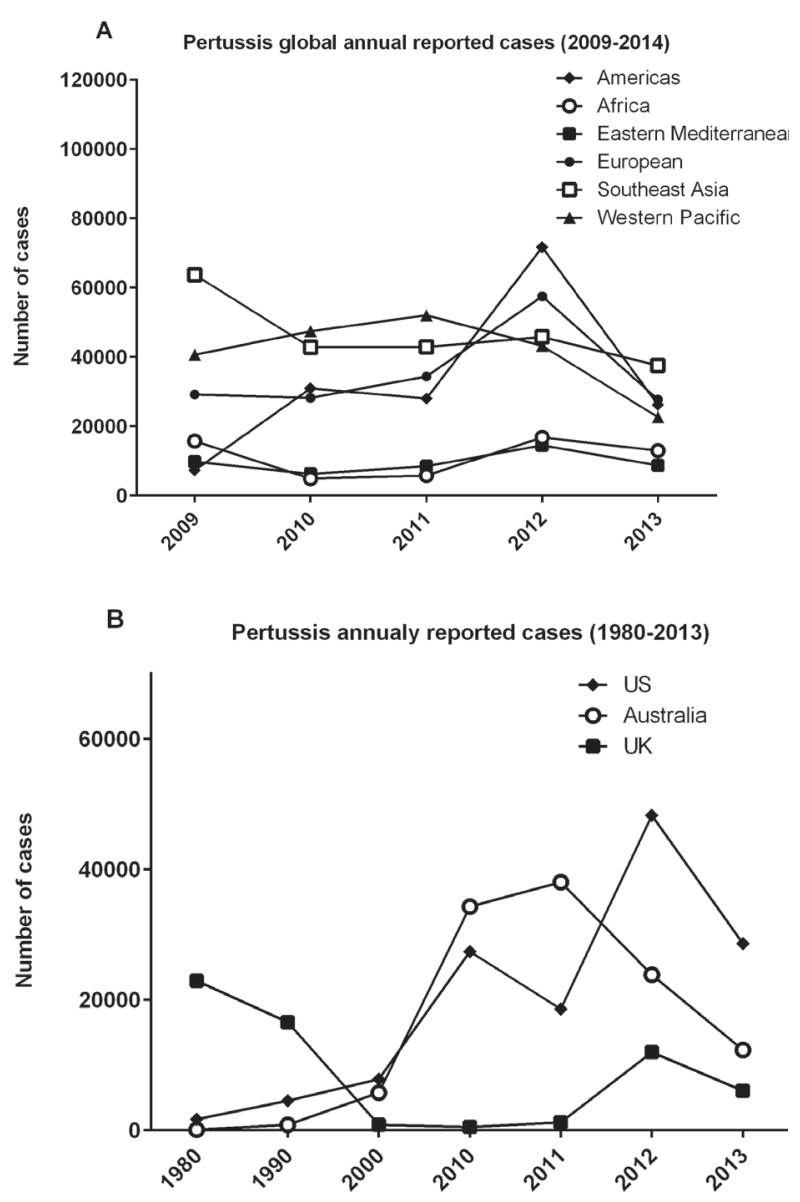

Figure 4 - Pertussis global annual cases. A, annual cases in the world (2009-2013), countries are distributed by regions; B, pertussis cases in the US, Australia and UK (1980-2013); data summarized from WHO (2014) and CDC (2014); http://apps. who.int/immunization_monitoring/globalsummary; http:// www.cdc.gov/pertussis/outbreaks/trends.html

these factors may contribute to the misdiagnosis of pertussis in several areas, including Brazil.

Disease surveillance, with standardized, biological diagnostic methods, is required. Such diagnosis must be both sensitive and specific. In addition, improvement of the vaccine to induce long-term immunity is urgent (Melvin et al. 2014, Guiso 2014, Burns et al. 2014).

\section{DIPHTHERIA}

Diphtheria is an infection of the upper respiratory tract caused by Corynebacterium diphtheriae. Besides the throat, the microbe may be isolated 
from leishmaniotic ulcers, and other atypical body sites, such as the ears, conjunctiva, vagina, sperm, heart valves and in cancer patient lesions (MattosGuaraldi et al. 2003, 2011, Mishra et al. 2005, Gomes et al. 2009, Ganeshalingham et al. 2012, Berger et al. 2013).

The major virulence factor of $C$. diphtheriae is the diphtheria toxin, a potent molecule of $58 \mathrm{kDa}$ witch a systemic effect lead to protein synthesis inhibition and cell death, especially in high perfusion organs. The vaccine formulation contains inactivated toxin (toxoid) adsorbed on aluminum hydroxide and conserved with thimerosal (NNii 2014). Between 1920 and 1950, widespread vaccination was implemented across Western Europe, Russia and North America resulting in a significant reduction of diphtheria incidence, and the onset of World War II coincided with the last diphtheria pandemic in western civilized countries. In Brazil, the disease incidence dropped gradually since the 80 's, but it is still endemic (Fig. 2C) (Mattos-Guaraldi et al. 2003, WHO 2014g). As a consequence of these widely implemented vaccination programs, global diphtheria incidence declined approximately $70 \%$ between 1970 and 1980 (Rappuoli et al. 2014, Ganeshalingham et al. 2012).

Despite the successful immunization program against diphtheria, the disease returned massively in the 1990s with more than 150,000 cases and around 4000 deaths (1990-1998) in the Russian Federation and the newly independent States of the former Soviet Union (Galazka 2000, Zakikhany and Efstratiou 2012). Many factors contributed to the 1990s epidemic, including reduced vaccination coverage, increased adult susceptibility, large population movements and lack of adequate treatment and prevention (Zakikhany and Efstratiou 2012).

Despite the implementation of widespread immunization, diphtheria remains endemic in some regions such as southeast Asia, with more than 3.750 cases reported in 2010 (WHO 2014k).
Although vaccination protects against toxin tissue damage, it does not prevent colonization or infection by the bacteria, thus immunized people may get ill or become asymptomatic carriers. The effectiveness of toxoid vaccination varies from $45 \%$ to $90 \%$. It remains unclear however, why vaccinated people develop the disease. Some authors argue that mutations in the toxin gene reduce the effectiveness of the vaccine and that the genetic diversity of $C$. diphtheriae favors the emergence of outbreaks. It is possible that epidemic clones, different from the strain of $C$. diphtheriae biovar. mitis Park-Williams (PW8), which is used in the production of the vaccine are not sensitive to vaccine induced immune response. In addition, the increased number of diseases caused by nontoxin producer $C$. dipthehriae alert to the necessity of studies for the development of more complete or alternative vaccine formulation (Wagner et al. 2012, Zakikhany and Efstratiou 2012, Zasada 2013).

Due to the high degree of susceptibility of children to diphtheria, vaccination at an early age is universally recommended (Fredlund et al. 2011). However, the concentration of protective antibodies by the age of 14 years old is $50 \%$ lower than what is observed in younger children, and in adults protective antibodies decreases around $10 \%$ per year, therefore the development of new and better vaccines is necessary mainly for the elderly population. The second population with a high need of vaccines is adolescents (Rappuoli et al. 2014). For this reason, many countries, including Brazil, recommends booster doses of the vaccine every 10 years (SBIM 2014). Studies showed that to prevent disease outbreaks, it is necessary that $90 \%$ of children and $75 \%$ of adults exhibit satisfactory levels of antitoxin antibodies, i.e., $0.01 \mathrm{IU} / \mathrm{mL}$ of serum circulating antitoxin (Damasco et al. 2005, Pimenta et al. 2006).

Thus, more effective immunization strategies are necessary, aimed at all ages, ethnic and social groups. National and international serological 
studies have highlighted a reduction in the immunity of adults (Pimenta et al. 2006, Sears et al. 2012).

However, even with the visible progress in global public health, there are still many reports arising from lack of vaccination. In Pakistan, an endemic zone, the general conception about diphtheria among the population is that it is a childhood disease (Faryal et al. 2013).

However, the circulation of toxigenic strains is still observed in all parts of the world, posing a constant threat to the population with low levels of seroprotection, and the occurrence of diphtheria is characterized by periodicity and epidemic waves, with a high incidence and mortality (Zakikhany and Efstratiou 2012).

Furthermore, toxigenic $C$. diphtheriae isolated from unusual non-respiratory sites, such as, urethritis involving toxigenic $C$. diphtheria transmitted by orogenital contact (Berger et al. 2013), may result in unusual manifestations of diphtheria-like disease. Thus, prompt subsequent public health actions are necessary.

\section{TUBERCULOSIS}

Tuberculosis (TB) is a chronic lower respiratory tract infection caused by Mycobacterium tuberculosis (Mtb). Besides the lungs, Mtb may achieve other organs, generating a wide range of clinical disease manifestations (Golden and Vikram 2005, Pfyffer and Palicova 2011). Despite the fact that TB is a threat to humans since antiquity, and one of the major causes of morbidity and mortality worldwide for centuries, there is neither effective vaccine nor treatment to stop the ongoing pandemic. In 2013, an estimated 9.0 million people developed TB and 1.5 million died from the disease (WHO 2014i). In 1993, WHO declared tuberculosis a global emergency.

Mtb is an intracellular microbe that infects alveolar macrophages. Approximately $70 \%$ of Mtb-exposed individuals will clear the bacteria, some will develop the disease and most of them will develop latent TB or non-clinical TB, where the bacteria remains physiologically inactive or dormant in the host (Cayabyab et al. 2012).

Latency is established by tuberculous granuloma formation, composed of a large number of immune cells - such as epithelial macrophages, neutrophils, T and B cells - which, altogether with a fibrous cuff, restrain Mtb from spreading. Only a fraction $(5-10 \%)$ of latently infected hosts develop TB and can potentially infect new hosts (Barry et al. 2009). Latent TB is quite difficult to diagnose and according to the Centers for Disease Control and Prevention (CDC), one third of the world's population is infected with Mtb (CDC 2014d).

Reactivation of the latency is associated with changes in host's immune response and it is particularly threating for patients with some immunodeficiency. HIV infected individuals for example are more susceptible to developing latent TB reactivation in 20- to 37-fold, suggesting that the HIV pandemic may contributes to the maintenance of TB worldwide (Getahun et al. 2010). TB is the main cause of death in HIV patients $(\sim 29 \%)$ (Pawlowski et al. 2012).

Additionally, the augmenting number of cases of TB caused by multidrug-resistant (MDR-TB) and extremely drug-resistant (XDR-TB) Mtb also contributes to disease burden. MDR-TB is defined as resistance to, at least, isoniazid and rifampicin among first-line drugs, while XDR-TB refers to MDR-TB with additional resistance to, any fluoroquinolone and at least one of three secondline injectable drugs (i.e. capreomycin, kanamycin and amikacin). Their development is mainly associated with inadequate and inappropriate use of antimicrobial therapy (WHO 2014j). Globally, the proportion of new cases with MDR-TB was 3.5\% in 2013 and has not changed in recent years. However, some countries (especially in Eastern Europe and the Russian Federation) are experiencing serious MDR-TB epidemics. This translates into an estimated 480.000 people having developed MDRTB in 2013. On average, an estimated $9.0 \%$ of them had XDR-TB. (WHO 2014j). 
Social marginalization is often responsible for limited access to health services leading to diagnostic delay, clinical worsening and poor adherence to treatment, and eventually to a less favourable outcome (Sulis et al. 2014). Therefore, poverty is not only one of the major causes of MDR-TB, but it is also one of the great barriers to treatment, making MDR-TB a huge challenge on TB eradication.

Recent observations suggest that environmental tobacco smoke (ETS) is a risk factor for TB. Smoking leads to faster and more severe progression of tuberculosis, but it is still unclear if the cigarette smoke (CS) compromises anti-TB immunity, increases $M t b$ transmission or both (Altet-Gômez et al. 2005, Chan et al. 2014, Davies et al. 2006). In addition, passive smoking seems to be an important risk factor for TB especially in children (Lin et al. 2007).

Although drugs and diagnostic tests have an essential place in disease control, the best way to control any infectious disease is through preventive vaccination, however, the current vaccine, bacillus Calmette-Guerin (BCG), is far from adequate.

The main limitation of BCG is that it confers limited and highly variable levels of protection against pulmonary disease. Because of its side effects, BCG was removed from the vaccination schedule in several countries, such as US and Australia. Nevertheless, when administered at birth, BCG protects against severe disease, particularly tuberculous meningitis, in the first decade of life (Nunes-Alves et al. 2014). That is particularly important in countries where the disease is endemic, such as in Brazil.

The BCG vaccine, is generally contraindicated at all levels of immunosuppression. Severe adverse effects of BCG vaccination are extremely rare in immunocompetent children however immunocompromised hosts such as HIVinfected individuals or those suffering a primary immunodeficiency tend to be unresponsive to treatment. Thus, BCG vaccination should be delayed when a primary immunodeficiency is suspected and/or a newborn has a family history of primary immunodeficiency. Primary immunodeficiency such as IL-12/IFN- $\gamma$ axis defects, granulomatous disease, severe combined immunodeficiencies (SCID) and idiopathic CD4 lymphopenia, increase the susceptibility of individuals to mycobacterial infections (Santos et al. 2010).

Hence, current strategies involve incorporating BCG into a new vaccine regimen, either by boosting BCG with subunit vaccines comprising either protein-adjuvant combinations or recombinant viral vectors (Aagaard et al. 2011; McShane et al. 2004) by developing genetically improved, safer, more effective strains of BCG or by attenuating Mtb strains (Martin et al. 2006). Ultimately, the best vaccine must find a solution to the problem of latency and immune evasion which is fundamental to destroy hidden $M t b$ within the population and, therefore, critical for TB eradication (Cayabyab et al. 2012).

The emergence of MDR-, XDR and now totally drug- resistant Mtb strains, the HIV epidemic and the lack of efficient vaccine for adults may explain why TB still epidemic.

\section{CONCLUSION}

Despite the efforts of global health organizations, several areas of the world are facing serious challenges, such as wars, poverty; inexistent infrastructures for vaccine manufacturing or difficulties in receiving imported vaccines. Additionally, the increase in the number of cases of vaccine preventable diseases is not restricted to poor countries or the ones in war. Economically developed and healthy sustainable countries, such as Canada, US and Australia are also experiencing the resurgence of diseases that were considered eliminated.

Although most of the current vaccines are effective, researchers are developing ways to increase the effectiveness of vaccine formulations, to innovate delivery systems, reduce the cost and develop better methods for vaccine conservation 
to prevent degradation. In addition, new vaccines are urgently needed for several other diseases, such as HIV/AIDS, dengue, ebola, malaria and leishmaniasis.

Vaccines are still the best way to prevent catastrophic infectious diseases. The maintenance of high vaccination coverage rates is necessary to eradicate vaccine-preventable diseases globally. Importantly, vaccination brings benefits to individuals, once it protects the person that has been vaccinated, and helps to protect vulnerable members of the population who cannot receive all vaccines, such as immunocompromised and the very young.

\section{RESUMO}

A introdução da vacinação no mundo reduziu drasticamente a incidência de doenças causadas por bactérias e vírus patogênicos. Apesar das estratégias de vacinação de grande sucesso, o número de casos de doenças que podem ser prevenidas por vacinas tem aumentado na última década e algumas destas doenças permanecem endêmicas em diferentes países. Aqui discutimos alguns aspectos epidemiológicos e possíveis argumentos que possam explicar porque doenças da antiguidade como, sarampo, pólio, coqueluche, difteria e tuberculose, permanecem entre nós.

Palavras-chave: difteria, sarampo, coqueluche, pólio, tuberculose, vacina.

\section{REFERENCES}

Aagahrd C, Hoang T, Dietrich J, Cardona PJ, Izzo A, Dolganov G, SCHOOLNIK GK, CASSIDY JP, BILlESKoV R AND ANDERSEN P. 2011. A multistage tuberculosis vaccine that confers efficient protection before and after exposure. Nat Med 17(2):189-194.

Albert MR, Ostheimer KG And Breman JG. 2001. The last smallpox epidemic in Boston and the vaccination controversy. N Engl J Med 344(5): 375-379.

ALteT-Gômez MN, AlcAide J, Godoy P, ROMERo MA AND HERNÁNDEZ DEL REY I. 2005. Clinical and epidemiological aspects of smoking and tuberculosis: a study of 13.038 cases. Int J Tuberc Lung Dis 9(4): 430-436.

AYlWard RB AND AlWAn A. 2014. Polio in Syria. Lancet 383(9916): 489-491.
BAKER J. 2003. The pertussis vaccine controversy in Great Britain, 1974-1986. Vaccine 21: 4003-4011.

BARry CE, BoshofF HI, DARTOIS V, Dick T, EHRT S, FLYNN J, SCHNAPPINGER D, WILKINSON RJ AND YOUNG D. 2009. The spectrum of latent tuberculosis: rethinking the biology and intervention strategies. Nat Rev Microbiol 7(12): 845855.

Berger A, Lensing C, Konrad R, Huber I, Hogardt M AND SING A. 2013. Sexually transmitted diphtheria. Sex Transm Infect 89(2): 100-101.

BeTÁKOVÁ T, SVETLíKOVÁ D AND GocNíK D. 2013. Overview of measles and mumps vaccine: origin, present, and future of vaccine production. Acta Virol 57(2): 91-96.

Burns DL, Meade BD and MessionNIER NE. 2014. Pertussis resurgence: perspectives from the working group meeting on pertussis on the causes, possible paths forward, and gaps in our knowledge. JID 209(Suppl 1): S32-S35.

Butler D. 2013. Polio risk looms over Europe. Nature 502(7473): 601-602.

Cayabyab MJ, Macovei L and Campos-Neto A. 2012. Current and novel approaches to vaccine development against tuberculosis. Front Cell Infec Microb 2: 154.

CDC. 2014a. Measles cases and outbreaks. http://www.cdc. gov/measles/cases-outbreaks.html

CDC. 2014b. Frequently asked questions about thimerosal (ethyl mercury). http://www.cdc.gov/vaccinesafety/ Concerns/Thimerosal/thimerosal faqs.html

CDC. 2014c. Vaccine Safety Datalink (VSD) Project Priority Studies. http://www.cdc.gov/vaccinesafety/Activities/ VSD.html

CDC. 2014d. Tuberculosis. http://www.cdc.gov/tb/

CDC. 2014e. Pertussis outbreak trends. http://www.cdc.gov/ pertussis/outbreaks/trends.html

Chan ED, Kinney WH, Honda JR, Bishwakarma R, Gangavelli A, Mya J, Bai X And Ordway DJ. 2014. Tobacco exposure and susceptibility to tuberculosis: Is there a smoking gun? Tuberculosis 94(6): 544-550.

Clark TA. 2014. Changing pertussis epidemiology: everything old is new again. JID 209(7): 978-981.

Clements CJ, Greenough P And Shull D. 2006. How vaccine safety can become political - the example of polio in Nigeria. Curr Drug Safety 1(1): 117-119.

DAmasco PV, Pimenta FP, Filardy AA, BRITo SM, ANDrade AF, LOPES GS, HiRATA JR R AND MATtosGuaraldi AL. 2005. Prevalence of $\mathrm{IgG}$ diphtheria antitoxin in blood donors in Rio de Janeiro. Epidemiol Infec 133(5): 911-914.

DAVIES PD, YeW WW, Ganguly D, Davidow AL, REICHMAN LB, DHEDA K AND RoOK GA. 2006. Smoking and tuberculosis: the epidemiological association and immunopathogenesis. Trans R Soc Trop Med Hyg 100(4): 291-298. 
FARYAL R, NOREEN Z, TAHIR F AND ZAHID-UR-REHMAN. 2013. Seroprevalence of Corynebacterium diphtheriae among vaccinated population of Rawalpindi/Islamabad, Pakistan. Pak J Pharm Sei 26(3): 649-651.

FREDLUND H, NORÉN T, LEPP T, MORFELDT EAND HENRIQUES NORMARK B. 2011. A case of diphtheria in Sweden, October 2011. Euro Surveill 16(50): 20038.

GALAZKA A. 2000. The changing epidemiology of diphtheria in the vaccine era. J Infect Dis 181(Suppl1): S2-9.

Ganeshalingham A, Murdoch I, Davies B And Menson E. 2012. Fatal laryngeal diphtheria in a UK child. Arch Dis Child 97(8): 748-749.

Gangarosa EJ, Galazka AM, Wolfe CR, Phillips LM, Gangarosa RE, Miller E AND CHEN RT. 1998. Impact of anti-vaccine movements on pertussis control: The untold story. The Lancet 351(9099): 356-361.

Getahun H, GunNeberg C, Granich R AND NunN P. 2010. HIV infection-associated tuberculosis: the epidemiology and the response. Clin Infect Dis 50(Suppl.3): S201-S207.

GodleE F, SMITH J AND MARCOVITCH H. 2011. Wakefield's article linking MMR vaccine and autism was fraudulent. BMJ 342: c7452.

GOLDEN MP AND VIKRAM HR. 2005. Extrapulmonary Tuberculosis: An overview. Amer Fam Physician 72(9): 1761-1768.

Gomes DL ET AL. 2009. Corynebacterium diphtheriae as an emerging pathogen in nephrostomy catheter-related infection: evaluation of traits associated with bacterial virulence. J Med Microbiol 58(11): 1419-1427.

GuISO N. 2014. Bordetella pertussis: Why is it still circulating? J Infec 68: S119-24.

HACKeTt AJ. 2008. Risk, its perception and the media: The MMR controversy. Community Pract 81(7): 22-25.

HARTZELL JD AND BLAYLOCK JM. 2014. Whooping Cough in 2014 and Beyond. Chest 146(1): 205-214.

HiSTORY OF VACCINES. 2014. http://www.historyofvaccines. org/content/articles/history-anti-vaccination-movements

JEGEDE AS. 2007. What led to the Nigerian boycott of the polio vaccination campaign? PLOS Med 4(3): e73.

LANG PO AND ASPINALL R. 2012. Immunosenescence and herd immunity: with an ever-in-creasing aging population do we need to rethink vaccine schedules? Expert Rev Vaccines 11(2): 167-176.

Lin HH, EzZaTi M AND MurRay M. 2007. Tobacco Smoke, Indoor Air Pollution and Tuberculosis: A Systematic Review and meta-analysis. PLoS Med 4(1): e20.

Maglione MA, Das L, RaAen L, Smith A, Chari R, Newberry S, Shanman R, Perry T, Goetz MB and GIDENGIL C. 2014. Safety of vaccines used for routine immunization of U.S. children: a systematic review. Pediatrics 134(2): 325-337.

MALTEZOU HC AND WiCKER S. 2013. Measles in health-care settings. Am J Infect Control 41(7): 661-663.
MARTIN C ET AL. 2006. The live Mycobacterium tuberculosis phoP mutant strain is more attenuated than BCG and confers protective immunity against tuberculosis in mice and guinea pigs. Vaccine 24(17): 3408-3419.

MatTos-GuARALDI AL ET AL. 2011.Concurrent diphtheria and infectious mononucleosis: difficulties for management, investigation and control of diphtheria in developing countries. J Med Microbiol 60(11): 1685-1688.

Mattos-Guaraldi AL, Moreira LO, Damasco PV AND HIRATA JÚNIOR R. 2003. Diphtheria remains a threat to health in the developing world--an overview. Mem Inst Oswaldo Cruz 98(8): 987-993.

McShane H, Pathan AA, Sander CR, Keating SM, Gilbert SC, Huygen K, Fletcher HA And Hill AV. 2004. Recombinant modified vaccinia virus Ankara expressing antigen 85A boosts BCG-primed and naturally acquired antimycobacterial immunity in humans. Nat Med 10(11): 1240-1244.

Melvin JA, Scheller EV, Miller JF AND CotTer PA. 2014. Bordetella pertussis pathogenesis: current and future challenges. Nature Rev Microbiol 12(4): 274-288.

Mills KGH, Ross PJ, Allen AC AND WiLK MM. 2014. Do we need a new vaccine to control the re-emergence of pertussis? Trend Microbiol 22(2): 49-52.

Mishra B, Dignan RJ, Hughes CF AND Hendel N. 2005. Corynebacterium diphtheriae endocarditis--surgery for some but not all! Asian Cardiovasc Thorac Ann 13(2): 119-126.

NNii. 2014. Diphtheria, Tetanus, Pertussis (DTaP) http://www. immunizationinfo.org/vaccines/diphtheria

Nunes-Alves C, Booty MG, CARPENTER SM, JAYARAMAN P, ROTHCHILD AC AND BEHAR SM. 2014. In search of a new paradigm for protective immunity to TB. Nat Rev Microbiol 12(4): 289-299.

Owais A, Asif Raza Khowaja AR, Syed Asad Ali AND ZAIDI ANITA KM. 2013. Review Pakistan's expanded program on immunization: An overview in the context of polio eradication and strategies for improving coverage. Vaccine 31(33): 3313-3319.

PARMET WE, GOODMAN RA AND FARBER A. 2005. Individual rights versus the public's health - 100 years after Jacobson v. Massachusetts. N Engl J Med 352(7): 652-653.

Pawlowski A, JANSSON M, SKold M, RotTenberg ME AND KalleniUs G. 2012. Tuberculosis and HIV co- infection. PLoS Pathog 8(2): e1002464.

Pfyffer GE AND PAlicova F. 2011. Mycobacterium: General Characteristics, Laboratory Detection, and Staining Procedures. In: Versalovic J, Carroll KC, Funke G, Jorgensen JH, Landry ML and Warnock DW (Eds), Manual of Clinical Microbiology. $10^{\text {th }}$ ed. Washington, DC: ASM Press 472.

Pimenta FP, Damasco PV, Cerbino Neto J, Lopes GS, Hirata JR R, Milagres LG AND Mattos-Guaraldi AL. 
2006. Diphtheria-neutralizing antibody levels in healthy adults from Rio de Janeiro, Brazil. Mem Inst Oswaldo Cruz 101(4): 459-462.

Polonsky JA, Singh B, Masiku C, Langendorf C, Kagoli M, Hurtado N, Berthelot M, Heinzelmann A, Puren A AND GRAIS RF. 2015. Exploring HIV infection and susceptibility to measles among older children and adults in Malawi: a facility-based study. Int J Infect Dis 31: 61-67.

Rappuoli R, Pizza M, Del Giudice G and De Gregorio E. 2014. Vaccines, new opportunities for a new society. PNAS 111(34): 12288-12293.

RoBERTS L. 2014. A war within a war. Science 343(6177): 1302-1305.

RodGers DV, GINDLER JS, ATKINSON WL AND MARKOWITZ LE. 1993. High attack rates and case fatality during a measles outbreak in groups with religious exemption to vaccination. Pediatr Infect Dis J 12(4): 288-292.

RUTTER PD AND Donaldson LJ. 2014. Mandatory polio vaccination for travellers: protecting global public health. The Lancet 383 (9930): 1695-1697.

SALMON DA AND OMER SB. 2006. Individual freedoms versus collective responsibility: Immunization decision making in the face of occasionally repeating values. Emerg Themes Epidemiol 3: 13.

SALMON DA AND SIEGEL AW. 2001. Religious and philosophical exemptions from vaccine requirements and lessons learned from conscientious objectors from conscription. Public Health Rep 116(4): 289-295.

Santos A, Dias A, Cordeiro A, Cordinhã C, Lemos S, Rocha G AND FARIA E. 2010. Severe axillary lymphadenitis after BCG vaccination: alert for primary immunodeficiencies. J Microbiol Immunol Infect 43(6): 530-537.

SBIM. 2014. Vacinação. Calendário SBIM. http://www.sbim. org.br/vacinacao/

Sears A, Mclean M, Hingston D, Eddie B, Short P AND JONES M. 2012. Cases of cutaneous diphtheria in New Zealand: implications for surveillance and management. $\mathrm{N}$ Z Med J 125(1350): 64-71.

SHERIDAN SL, WARE RS, GRIMWOOD K AND LAMBERT SB. 2012. Number and order of whole cell pertussis vaccines in infancy and disease protection. JAMA 308(5): 454-456.

Stratton K, Gable A, Shetty P and Mccormick M. 2001. Immunization safety review: Measles-mumpsrubella vaccine and autism. Washington, DC: Institute of Medicine, National Academies Press.

Sulis G, Roggi A, MatteElli A And RaViglione MC. 2014. Tuberculosis: Epidemiology and Control. Mediterr J Hematol Infect Dis 6(1): e2014070.

WAGNER KS, WHITE JM, LUCENKO I, MERCER D, CROWCROFT NS, NeAl S AND EFstratiou A. 2012. Diphtheria in the postepidemic period, Europe, 2000-2009. Emerg Infect Dis 18(2): $217-225$.
WAKefield AJ AND Montgomery SM. 2001. Measles, mumps, and rubella vaccine: Through a dark glass, darkly. Adverse Drug React Toxicol Rev 19(4): 265-283.

WAKEFIELD AJ ET AL. 1998. Ileal-lymphoid-nodular hyperplasia, non-specific colitis, and pervasive developmental disorder in children. Lancet 351(9103): 637-641.

WARFEL JM, Zimmerman LI AND MERKeL TJ. 2013. Acellular pertussis vaccines protect against disease but fail to prevent infection and transmission in a nonhuman primate model. PNAS 111(2): 787-792.

WARRAICH HJ. 2009. Religious opposition to polio vaccine. Emerg Infect Dis 15(6): 978.

WHO. 2014a. Polio global eradication initiative. http://www. polioeradication.org/http

WHO. 2014b. Measles. http://www.who.int/topics/measles/en/

WHO. 2014c. Measles reported cases http://apps.who.int/ immunization_monitoring/globalsummary/timeseries/ tsincidencemeasles.html

WHO. 2014d. Poliomyelitis. http://www.who.int/mediacentre/ factsheets/fs $114 / \mathrm{en} /$

WHO. 2014e. Case breakdown by country. http://www. polioeradication.org/dataandmonitoring/poliothisweek.aspx

WHO. 2014f. Health topics. Pertussis. http://www.who.int/ topics/pertussis/en/

WHO. 2014g. WHO vaccine-preventable diseases: monitoring system. 2014 global summary. http://apps.who.int/ immunization_monitoring/globalsummary

WHO. 2014h. Biologicals. Acellular pertussis vaccines http:// www.who.int/biologicals/areas/vaccines/apertussis/en/

WHO. 2014i. Tuerculosis. http://www.who.int/tb/publications/ global_report/en/

WHO. 2014j. Multidrug-resistant tuberculosis (MDR-TB) http://www.who.int/tb/challenges/mdr/en/

WHO. 2014k. Global and regional immunization profile. Number of reported cases. http://www.who.int/ immunization/monitoring_surveillance/data/gs seaprofile.pdf?ua=1

WiLliamson S. 1984. Anti-vaccination leagues. Arch Dis Child 59(12):1195-1196.

Witt MA, ARIAs L, KATz PH, TRUONG ET AND WitT DJ. 2013. Reduced risk of pertussis among persons ever vaccinated with whole cell pertussis vaccine compared to recipients of acellular pertussis vaccines in a large US cohort. Clin Infect Dis 56(9): 1248-1254.

WOLFE RM AND SHARPE LK. 2002. Anti-vaccinationists past and present. BMJ 325(7361): 430-432.

ZaKikHANY K AND EfStratiou A. 2012. Diphtheria in Europe: current problems and new challenges. Future Microbiol 7(5): 595-607.

ZASADA AA. 2013. Nontoxigenic highly pathogenic clone of Corynebacterium diphtheriae, Poland, 2004-2013. Emerg Infect Dis 19(11): 1870-1872. 